\title{
AVALIAÇÃO DOS RESULTADOS OBTIDOS COM A IMPLANTAÇÃO DO PROGRAMA CRIANÇA ECOLÓGICA NA FLORESTA ESTADUAL DE BEBEDOURO (SP)
}

\author{
Alessandra Nicolau Pinheiro Fernandes ${ }^{1}$ \\ Mayra Cristina Prado de Moraes ${ }^{2}$ \\ Gabriela Galetti ${ }^{3}$ \\ Silvio César Moral Marques ${ }^{4}$ \\ Ismail Barra Nova de Melo ${ }^{5}$
}

Resumo: Neste trabalho realizou-se a avaliação dos resultados obtidos com a implantação do Projeto Estratégico de Educação Ambiental do Governo do Estado de São Paulo denominado Criança Ecológica, que foi executado pela Secretaria de Estado de Meio Ambiente (SMA) na Floresta de Bebedouro. Avaliou-se o resultado dos relatórios pós-visita elaborados pela Coordenadoria de Educação Ambiental da SMA, interpretando os dados das visitações de escolas e municípios, a divulgação da área e a satisfação dos visitantes, com o objetivo de se verificar através da comparação com as ações propostas pelo Projeto, se foram atingidas as metas na área de estudo.

Palavras-chave: Educação Ambiental; Ecopedagogia; Unidade de Conservação.

1 Mestre em Ciências Ambientais, UFSCar/PPGSGA. E-mail: alepinheiro.bio@hotmail.com

${ }^{2}$ Mestre em Ciências Ambientais, UFSCar/PPGSGA. E-mail: mayracpmoraes@gmail.com

${ }^{3}$ Mestre em Ciências Ambientais, UFSCar/PPGSGA. E-mail:gabi.18florestal@gmail.com

${ }^{4}$ Prof. Dr. do PPGSGA,UFSCar-Sorocaba. E-mail:silviocmm@ufscar.br

${ }^{5}$ Prof. Dr. do PPGSGA,UFSCar-Sorocaba. E-mail:ismail@ufscar.br 


\section{Introdução}

O Instituto Florestal implanta, desde 1978, em suas unidades de conservação espaços destinados a educação ambiental e recreação, como resultado da crescente demanda por tais atividades em áreas verdes e em atendimento às atribuições específicas da Secretaria de Estado do Meio Ambiente (SMA), do qual faz parte. A abertura das áreas de educação ambiental e recreação nessas unidades tem por objetivo contribuir para a melhoria da qualidade de vida ao oferecer maiores facilidades e oportunidades de lazer a população, promover a integração dessa população com a natureza, propiciar uma compreensão de sua ecologia e da necessidade de conservação através de programas educativos e subsidiar a complementação curricular aos alunos e professores. Assim cria-se uma interação benéfica onde os visitantes encontram oportunidade de conhecimento e relaxamento e a natureza passa a ser compreendida e respeitada, multiplicando-se a ideia da conservação. (HERCULANI et al., 2010).

Dentro dessa filosofia, muitas unidades implantaram dentro de seus planos de manejo, o Programa de Uso Público e Educação Ambiental, destacando-se como pioneira a Floresta de Assis (TABANEZ, 2000). Em 1992, ocorreu uma iniciativa de padronização institucional e direcionamento dos Programas de Uso Público, com a criação de um grupo de Educação Ambiental, cuja atribuição era definir diretrizes, objetivos e estratégias para o desenvolvimento de projetos de educação ambiental no interior das unidades de conservação e de produção, bem como junto às comunidades de entorno a estas (ARROMBA et al., 1992).

A Floresta Estadual de Bebedouro, situada em Bebedouro, SP, é uma unidade de conservação de uso sustentável administrada pela Secretaria do Meio Ambiente do Estado de São Paulo, através do Instituto Florestal. Sendo uma instituição oficial do Governo do Estado de São Paulo, tem em seu programa de manejo a educação ambiental como estratégia de gestão e integração entre a unidade de conservação e a comunidade onde está inserida (INSTITUTO FLORESTAL, s/d).

Em 2004, a Floresta Estadual de Bebedouro iniciou suas atividades de uso público e educação ambiental com a implantação de uma trilha denominada Trilha do Retiro, possuindo como atrativo a visitação a mata ciliar do Córrego do Retiro. No ano de 2005, instalou-se uma área de recreação com parquinho de madeira, eco pontos para separação de resíduos e mesas para lanche. A implantação de uma área de Educação Ambiental e Visitação Pública nesta floresta buscou desenvolver as potencialidades ambientais da unidade de conservação, através de transferência de conhecimentos técnicoscientíficos relacionados ao ambiente e através de implantação de infraestrutura para visitação e trilhas interpretativas (informação verbal) .

\footnotetext{
6 Notícia fornecida pela gestora da Floresta Estadual de Bebedouro em Dezembro de 2011.
} 
No ano de 2008, a Secretaria do Meio Ambiente do Estado de São Paulo (SMA) deu inicio a implantação de um Programa Institucional de Educação Ambiental, em conformidade com a Lei no 9795/99 que estabeleceu a Política Nacional de Educação Ambiental (BRASIL, 1999) e norteado pelas diretrizes da Agenda 21 Global, instituída na Conferência das Nações Unidas sobre Meio Ambiente e Desenvolvimento Humano (ECO-92) realizada em 1992, no Rio de Janeiro. Assim sendo, a Secretaria do Meio Ambiente criou através da Resolução SMA no 17, de 19 de março de 2008 (SÃO PAULO, 2008), 21 Projetos Ambientais Estratégicos da Secretaria do Meio Ambiente para a gestão ambiental do Estado de São Paulo e a Resolução SMA n 18 de 31 de março de 2009 (SÃO PAULO, 2009), que estabeleceu o Programa Criança Ecológica, como um projeto estratégico em Educação Ambiental para todas as unidades administradas pela SMA no Estado de São Paulo, ambas as Resoluções foram revogadas pela Resolução SMA $n^{\circ} 51$ de 08 de junho de 2010 (SÃO PAULO, 2010).

O projeto "Criança Ecológica" adere aos princípios da ecopedagogia para fomentação de uma nova cultura. Segundo o artigo $2^{\circ}$ da Resolução SMA 18 de 31/03 de 2009 o objetivo desse Projeto Ambiental Estratégico é de informar e sensibilizar as crianças do ensino fundamental I, de 8 a 10 anos sob os conceitos básicos da agenda ambiental, promovendo a mudança de comportamento e a afirmação de novas atitudes sustentáveis (BENEVIDES, 2003).

O Programa possui sete unidades pedagogicamente preparadas com monitores ambientais que recebem as excursões de alunos. Dentro do Programa há os projetos Vila Ambiental, Bicho Legal, Água Amiga, Verde Vivo, Floresta Legal e Pomar Urbano, todos possuem personagens ambientais que utilizam da proposta do educar para o fazer, que segundo Layrargues (2012), para difundir o aprendizado sobre ecologia e sustentabilidade.

Em agosto de 2009, a Floresta Estadual de Bebedouro aderiu ao programa com a implantação de um espaço educativo totalmente equipado e decorado para receber os grupos de alunos, conforme a proposta estabelecida no projeto.

Diante do presente contexto e devido à falta de trabalhos que mostrem resultados desse projeto, o objetivo deste trabalho foi avaliar se as metas do Projeto Estratégico Criança Ecológica- Programa Floresta Legal foram alcançadas na Floresta Estadual de Bebedouro.

\section{Material e Métodos}

A Floresta Estadual de Bebedouro, também conhecida como Horto Florestal, foi criada em 1925 e se classifica como uma unidade de conservação (UC) de uso sustentável, que segundo o Sistema Nacional de Unidades de Conservação da Natureza (SNUC) em seu artigo $2^{\circ}$, é uma categoria que visa à exploração do ambiente de maneira a garantir a perenidade dos recursos ambientais renováveis e dos processos ecológicos, mantendo a biodiversidade Revbea, São Paulo, V. 12, № 1: 12-23, 2017. 
e os demais atributos ecológicos, de forma socialmente justa e economicamente viável (BRASIL, 2000).

A UC possui uma área total de 96 hectares e localiza-se entre as coordenadas $20^{\circ} 57^{\prime} \mathrm{S}$ de latitude e $48^{\circ} 30^{\prime} \mathrm{W}$ de longitude, com altitude média de 550 metros; precipitação média anual por volta de $1450 \mathrm{~mm}$; clima tropical úmido (AW) e solo pertencente à unidade Latossolo Roxo (TABANEZ; ROSA, 1994).

No ano de 2008 a Floresta Estadual de Bebedouro recebeu apoios e parcerias para sua reforma de maneira a se enquadrar às propostas do programa Criança Ecológica- Floresta Legal. Foram instalados equipamentos eletrônicos, e confeccionados, pela SMA através da Coordenadoria de Educação Ambiental, materiais pedagógicos como cartilhas, adesivos e tatuagens com os personagens característicos do projeto. Foram contratados através de processo de terceirização dois monitores e um auxiliar administrativo e a coordenação do Espaço ficou a cargo da Gestão da Unidade, bem como a manutenção da trilha e limpeza do espaço.

Para o presente trabalho, primeiramente foi analisado se o Programa, de uma maneira geral, está de acordo com as leis vigentes de Educação ambiental, depois, avaliou-se como o programa se comportou na Floresta Estadual de Bebedouro, para isso foram obtidos dados sobre a divulgação da unidade de conservação pelo projeto, sobre a visitação e sobre a impressão dos visitantes com relação ao programa. Os períodos da coleta dos dados foram: agosto de 2008 a agosto de 2009 (ano anterior a implantação do programa) e agosto de 2009 a agosto de 2010 (primeiro ano de implantação do programa). A divulgação da unidade foi avaliada através da quantidade de vezes que a mesma foi citada na mídia eletrônica durante ambos os períodos.

Os dados de visitação ao Espaço Floresta Legal de Bebedouro foram obtidos da seguinte forma: identificou-se a quantidade de alunos nos grupos de visita; escola a que pertencem; municípios de origem e quantos e quais os municípios que retornaram à unidade em outra ocasião.

A avaliação sobre a impressão dos visitantes quanto ao programa foi obtida através dos questionários aplicados pelos monitores que atendem no Espaço da Floresta de Bebedouro, aos professores responsáveis pelos grupos visitantes após as visitas. Estes questionários foram elaborados pela Coordenadoria de Educação Ambiental da SMA, para diagnosticar e monitorar os espaços.

Outro modo de avaliação foi o levantamento das cidades, dentre as que visitaram a unidade, que obtiveram o Título de Município Verde Azul, pois o Criança Ecológica contava como atividade para pontuação nesse outro programa. O Programa Município Verde e Azul (SÃO PAULO, 2010) é um programa estratégico da SMA, cujos objetivos são classificar e pontuar os municípios do Estado de São Paulo de acordo com suas ações ambientais, estabelecendo assim um ranking estadual. As cidades melhores pontuadas recebem apoio para recursos do Governo do Estado de São Paulo. 


\section{Resultados e Discussão}

O Projeto Criança Ecológica está pautado na legislação vigente tanto na esfera nacional quanto estadual. Primeiramente, verificou-se que a PNEA estabelece em seu artigo $3^{\circ}$, inciso III que "aos órgãos integrantes do Sistema Nacional do Meio Ambiente - SISNAMA, promover ações de Educação Ambiental integradas aos programas de conservação, recuperação e melhoria do meio ambiente" (BRASIL, 1999). Neste sentido, o Projeto Estratégico Criança Ecológica se enquadra como ação institucional de Educação Ambiental da Secretaria do Meio Ambiente do Estado de São Paulo, que é integrante do SISNAMA.

No âmbito estadual, a Política Estadual de Educação Ambiental (Lei Estadual no 12.780/07), artigo 11, inciso VI, diz que uma das linhas de atuação para o desenvolvimento das ações de Educação Ambiental no Estado de São Paulo é através do desenvolvimento, acompanhamento e avaliação de programas e projetos (SÃO PAULO, 2007). O Programa Criança Ecológica foi concebido com sete programas que visam a difusão de informações das agendas ambientais: azul, que trabalha com a temática da água, verde, que trabalha com a temática da biodiversidade e das florestas, cinza, que trabalha a temática da poluição, amarela, que trabalha a temática das mudanças climáticas e aquecimento global. $\mathrm{O}$ acompanhamento e avaliação foi executado durante todo o projeto através dos depoimentos pós visita aos espaços e posteriormente enviavam essas respostas à coordenação geral do projeto, Coordenadoria de Educação Ambiental da SMA, mostrando que o intuito do Projeto está de acordo com as linhas de atuação para o desenvolvimento das ações de Educação Ambiental no Estado de São Paulo.

Sob o âmbito da divulgação da UC o Projeto Criança Ecológica deu a ela grande destaque principalmente na mídia eletrônica, meio de comunicação mais utilizado para sua divulgação. A SMA implantou um site para apresentação, informações e agendamento dos espaços do projeto em todos os programas que foram estabelecidos. Essa mídia foi utilizada por professores e diretores das escolas, para ter acesso a como chegar nesses espaços, o que iriam encontrar neles, a abordagem pedagógica que o projeto utilizava e até informações sobre meio ambiente no Ecoglossário.

A apresentação dos personagens também foi feita através do site, com apresentação colorida e linguagem de fácil compreensão. A televisão foi utilizada como dispersora das informações ambientais e do próprio site onde havia as informações para visitação dos espaços. Foram apresentados pequenos programas de um minuto em duas emissoras diferentes da rede televisiva, neles os personagens falaram sobre suas agendas com a apresentação de um casal de crianças da faixa etária do público alvo do projeto.

Houve menor abordagem em jornais e revistas, sendo que sua ocorrência foi maior no período da divulgação de inauguração dos espaços nos jornais regionais. 
Com relação à Floresta de Bebedouro, o levantamento dos dados de divulgação na mídia eletrônica está representado na Tabela 1. Esses dados foram obtidos através de registros disponíveis na internet e separados por data e assunto.

Tabela 1: Divulgação da Floresta de Bebedouro em mídia eletrônica antes (agosto/08 a agosto/09) e no primeiro ano do Projeto Criança Ecológica (agosto/09 a agosto/10).

\begin{tabular}{c|ccc}
\hline Mês/Ano & $\begin{array}{c}\mathbf{N}^{\circ} \text { total de links } \\
\text { sobre a UC }\end{array}$ & $\begin{array}{c}\text { Divulgação da UC } \\
\text { devido ao Projeto } \\
\text { Criança Ecológica }\end{array}$ & $\begin{array}{c}\text { Divulgação da UC } \\
\text { sobre outros } \\
\text { assuntos }\end{array}$ \\
\hline Agosto/08 a Agosto 09 & 18 & - & 18 \\
\hline Agosto/09 a Agosto/10 & 61 & 44 & 17 \\
\hline
\end{tabular}

Fonte: Os autores.

Segundo Oliveira e Nader (2007) a comunicação é essencial às questões ambientais, pois informa e conscientiza a população sobre sua relevância, promovendo assim um comprometimento público e uma nova relação do ser humano com a natureza. A mídia ou comunicação de massa tem essa capacidade de colaborar com a conscientização ambiental de quem a utiliza.

A divulgação da Floresta de Bebedouro aumentou significativamente após a implantação do Projeto Criança Ecológica. Grande parte das aparições da unidade se deu por conta de visitas de escolas que publicaram nos sites das prefeituras ou em seus próprios blogs relatos de sua experiência durante a visitação. Este retorno foi positivo, pois as publicações basearam-se nas impressões que os visitantes tiveram do local e da importância educativa do passeio, além da divulgação de fotos do mesmo.

De maneira geral ocorreu um marketing positivo, espontâneo e multiplicador onde foram transmitidos os conhecimentos adquiridos e as impressões dos visitantes, contribuindo assim para o incentivo da visita de outras escolas à unidade.

A análise quantitativa da visitação ao Programa Floresta Legal implantado na Floresta de Bebedouro realizou-se através da coleta dos dados do relatório mensal de visitas emitido pela unidade e encaminhado a SMA. Para a análise foram contabilizados os visitantes de doze meses anteriores à inauguração do Programa (Agosto/08 a Agosto/09), o primeiro ano do projeto (Setembro/09 a Agosto/10) e as visitações até o final do projeto (Setembro/10 a Dezembro/11). Os visitantes considerados para a pesquisa foram os alunos das escolas de ensino fundamental, os visitantes espontâneos não entraram para a estatística (Tabela 2).

Tabela 2: Visitação do espaço Floresta Legal de Bebedouro (agosto/2009 a agosto/2010).

\begin{tabular}{|l|c|}
\hline \multicolumn{1}{|c|}{ Período } & Visitantes \\
\hline agosto/2008 a agosto/2009 & 587 \\
\hline setembro/2009 a agosto/2010 & 4.913 \\
\hline
\end{tabular}

Fonte: Os autores. 
A quantidade total de alunos atendidos no primeiro ano de implantação do Projeto Criança Ecológica foi de 4913, ou seja, mais de oito vezes maior quando comparado ao ano anterior a implantação do mesmo. Já no segundo ano, a visitação foi $91 \%$ maior do que no primeiro ano. Esses números mostram que o Programa atraiu um público muito maior do que normalmente ocorria na UC. Essa estatística é muito positiva para a unidade, pois demostra que objetivos como promover a educação ambiental e interagir os visitantes com a natureza foram alcançados através da visitação.

Um total de 34 municípios visitou o projeto em Bebedouro durante o primeiro ano de implantação do programa (Tabela 3). Os municípios que tiveram maior frequência de visitas foram em primeiro lugar Olímpia, com 15 visitações, em segundo lugar Fernando Prestes, com 12 e em terceiro lugar Pirangi, com 11. O frequente retorno dessas cidades à Floresta Estadual de Bebedouro é positivo, demonstrando satisfação e interesse em introduzir o projeto a outras turmas.

Tabela 3. Municípios de origem, quantidades de alunos e $n^{\circ}$ de visitas ao espaço Floresta Legal de Bebedouro

\begin{tabular}{|c|c|c|}
\hline \multicolumn{3}{|c|}{ Agosto de 2009 a Agosto de 2010} \\
\hline Localidade & Quantidade de alunos & Número de visitas/turmas \\
\hline Altair & 100 & 2 \\
\hline Barretos & 142 & 4 \\
\hline Bebedouro & 191 & 6 \\
\hline Candido Rodrigues & 68 & 2 \\
\hline Cedral & 68 & 2 \\
\hline Colombia & 194 & 6 \\
\hline Cosmorama & 50 & 1 \\
\hline Fernando Prestes & 384 & 10 \\
\hline Fernandópolis & 95 & 2 \\
\hline Gal. Salgado & 65 & 1 \\
\hline Guaíra & 193 & 5 \\
\hline Guaraci & 153 & 4 \\
\hline Itajobi & 200 & 5 \\
\hline Marapoama & 80 & 2 \\
\hline Mesópolis & 68 & 2 \\
\hline Olímpia & 500 & 16 \\
\hline Onda Verde & 150 & 3 \\
\hline Orindiúva & 40 & 1 \\
\hline Paulo Faria & 157 & 4 \\
\hline Paraíso & 177 & 6 \\
\hline Pirangi & 412 & 12 \\
\hline Pitangueiras & 140 & 4 \\
\hline Populina & 40 & 1 \\
\hline Potirendaba & 96 & 3 \\
\hline Santa Adélia & 88 & 3 \\
\hline Severínia & 362 & 12 \\
\hline Sud Menuci & 28 & 1 \\
\hline Tabapuã & 40 & 1 \\
\hline Taiaçu & 80 & 2 \\
\hline Tanabi & 16 & 1 \\
\hline Taquaritinga & 24 & 1 \\
\hline Uchôa & 292 & 8 \\
\hline Viradouro & 55 & 2 \\
\hline Vista Alegre do Alto & 165 & 5 \\
\hline
\end{tabular}


A análise qualitativa em relação à visitação do Programa Floresta Legal na Floresta de Bebedouro realizou-se por meio dos depoimentos Pós Visita elaborados pela Coordenadoria de Educação Ambiental da SMA para os professores que acompanhavam as crianças durante a visitação. Estes questionários têm por finalidade o acompanhamento e avaliação dos visitantes sobre a visita aos Espaços do Projeto Criança Ecológica.

No questionário, composto por questões fechadas, mas abertas a comentários, avaliou-se o site e todo o sistema de agendamento, os recursos pedagógicos e o quanto eles despertaram a atenção dos visitantes, 0 atendimento dos monitores e o espaço físico onde eram executadas as atividades, sala de vídeo e trilha. No final do questionário havia um espaço para que os professores deixassem suas considerações finais, sugestões e críticas.

Foram analisados 89 questionários (Tabela 4), referentes às visitas do período estudado. Os questionários para análise foram disponibilizados pela administração da Floresta de Bebedouro.

Tabela 4: Avaliação de agendamento e recursos pedagógicos.

\begin{tabular}{ccccc}
\hline Quesitos & \multicolumn{4}{c}{ Avaliação do entrevistado } \\
\cline { 2 - 5 } & Muito Bom & Bom & Regular & Ruim \\
\hline Agendamento da visita & 80 & 09 & - & - \\
\hline $\begin{array}{c}\text { Recursos pedagógicos } \\
\text { adotados }\end{array}$ & 88 & 01 & - & - \\
\hline Dinâmica da visita & 85 & 01 & 03 & - \\
\hline
\end{tabular}

Fonte: Adaptado de São Paulo, 2009.

Em relação ao agendamento da visita e recursos pedagógicos, a classificação pelos entrevistados foi positiva, pois mais de $95 \%$ dos entrevistados mostraram-se satisfeitos com os quesitos apresentados.

Através da avaliação destes questionários pudemos observar que a visitação na Floresta Estadual de Bebedouro pautada pelo programa Criança Ecológica- Floresta Legal de uma maneira geral cumpriu com seus objetivos e foi satisfatória para os visitantes.

A Resolução SMA 55 de 11 de agosto de 2009, trata da alteração da denominação do Projeto Estratégico Município Verde para Município Verde Azul, onde a SMA institui um documento chamado de Termo de Adesão ao Protocolo de Intenções Município Verde Azul. Esse documento firma um compromisso voluntário das Prefeituras Municipais do Estado de São Paulo em inserir no planejamento e gestão ambiental do território sob sua jurisdição, a variável ambiental tomando por base dez Diretivas Ambientais definidas pela SMA. Dentre estas diretivas encontra-se a Educação Ambiental, por meio da diretiva cinco define-se que os municípios participantes devem estabelecer programa de educação ambiental para a rede pública de ensino municipal, promovendo também a informação e a conscientização da população a 
respeito da agenda ambiental, incluindo a participação nos programas ambientais a serem definidos pela Secretaria do Meio Ambiente.

Sendo assim, a SMA acoplou o Projeto Estratégico Criança Ecológica ao Projeto Estratégico Município Verde Azul, fazendo com que as prefeituras participantes tivessem interesse em mandar seus alunos aos espaços do projeto para pontuar na diretiva 5 , aumentando suas chances de obter a certificação de Município Verde Azul, que é o certificado a ser emitido pela Secretaria do Meio Ambiente atestando a excelência do Município frente às dez Diretivas Ambientais estabelecidas.

Em consulta ao ranking referente ao ano de 2010 de municípios paulistas que receberam a Certificação de Município Verde Azul, dentro do Projeto Estratégico da SMA, destacaram-se neste mesmo universo 13 municípios (Tabela 5):

Tabela 5: Classificação dos municípios que visitaram o Programa Floresta Legal de Bebedouro com relação a certificação junto ao Projeto Município Verde Azul no ano de 2010.

\begin{tabular}{cc}
\hline com relação a certificação junto ao Projeto Município Verde Azul no ano de 2010. \\
\hline Nome do Município & Colocação no ranking 2010 \\
\hline Paulo Faria & $3^{\circ}$ \\
\hline Orindiúva & $16^{\circ}$ \\
\hline Potirendaba & $17^{\circ}$ \\
\hline Viradouro & $27^{\circ}$ \\
\hline Guaraci & $29^{\circ}$ \\
\hline Pirangi & $47^{\circ}$ \\
\hline Barretos & $50^{\circ}$ \\
\hline Itajobi & $67^{\circ}$ \\
\hline Fernandópolis & $69^{\circ}$ \\
\hline Tanabi & $93^{\circ}$ \\
\hline Populina & $100^{\circ}$ \\
\hline Candido Rodrigues & 105 \\
\hline Tabapuã & $118^{\circ}$
\end{tabular}

Fonte: Adaptado de São Paulo (2009).

Dentre os 34 municípios que visitaram o espaço Floresta Legal na Floresta Estadual de Bebedouro, 13 já possuem Certificação de Município Verde Azul. Alguns deles não possuíam essa certificação até então, ou tinham uma posição muito abaixo da atual. Os municípios aumentaram sua pontuação devido ao cumprimento da diretiva 5 através das visitações ao espaço Floresta Legal de Bebedouro. A classificação dessas cidades no ranking é muito satisfatória, já que participam desse Programa 645 munícipios de todo o estado de São Paulo. 


\section{Conclusões}

Em um ano de desenvolvimento do Programa, a Floresta de Bebedouro foi citada muitas vezes pela mídia eletrônica, ampliando sua divulgação e recebeu em seu espaço um total de 4.913 crianças, além de professores e coordenadores, aumentando $91 \%$ no segundo ano do projeto.

A satisfação dos visitantes ficou provada através da avaliação dos Depoimentos Pós Visitas, respondidos pelos professores ao final de cada visita. O interesse pela conservação ambiental também ficou evidenciado na análise dos municípios que visitaram o espaço e implantaram outras ações ambientais, tendo como incentivo direto a Certificação de Município Verde Azul. O ganho de pontuação para obter essa certificação foi um ponto de grande relevância para que aumentasse a adesão dos municípios nas frequentes visitas a Floresta Estadual de Bebedouro.

Outro fato observado foi a quantidade de vezes que alguns municípios retornaram com novos alunos, numa clara demonstração de que o espaço se mostrou acolhedor e proporcionou boas experiências aos visitantes e que a abordagem pedagógica não decepcionou os coordenadores de escolas e professores, que motivaram-se a participar novamente com outras turmas.

Através da Resolução SMA no 02 de 06 de janeiro de 2012, a SMA institui o Projeto EcoGalera no âmbito do Programa Estadual de Educação Ambiental em conformidade com o Programa Estadual de Educação Ambiental. O Projeto EcoGalera atenderá as crianças e adolescentes, entre 06 (seis) a 12 (doze) anos de idade, sobrepondo-se ao público anteriormente abrangido pelo Programa Criança Ecológica que era de 08 a 10 anos. Assim, a Floresta de Bebedouro não pode mais ter o Programa Criança Ecológica em suas ações e atividades de educação ambiental.

Assim sendo, mesmo com sua substituição, concluiu-se que o Projeto Criança Ecológica implantado na Floresta de Bebedouro atingiu os objetivos propostos e demonstrou-se uma eficiente ferramenta de divulgação da unidade de conservação e das atividades de educação ambiental, ficando comprovada a sua pertinência dentro dos 21 Projetos Estratégicos elaborados pela SMA para a Gestão Ambiental de São Paulo.

\section{Referências}

ARROMBA, A.L. et al. Diretrizes para os Programas de Uso Público do Instituto Florestal do Estado de São Paulo - SMA. CONGRESSO NACIONAL SOBRE ESSÊNCIAS NATIVAS, São Paulo, 1992. Anais... São Paulo: UNIPRESS 1992. p. 1076-1080. Revista Instituto Florestal, v. 4, n. único, 66 p., 1992.

BENEVIDES, M.V. Nós, o povo. Reformas políticas para radicalizar a democracia. In: BENEVIDES, M.V. et al. Reforma política e cidadania. São Paulo: Fundação Perseu Abramo, 2003.

revista brasileira educação ambiental 
BRASIL. Lei no 9.795, de 27 de abril de 1999. Dispõe sobre a Educação Ambiental, institui a Política Nacional de Educação Ambiental e dá outras providências. Disponível em: http://www.planalto.gov.br/ccivil 03/leis/19795.htm. Acesso em: outubro de 2013.

BRASIL. Ministério do Meio Ambiente. Lei no 9985, de 18 de julho de 2000. Dispõe sobre a Instituição do Sistema Nacional de Unidades de Conservação da Natureza- SNUC. Brasília, DF, 2000. 32 p.

HERCULANI, S.; ESTON, M.R.; ANDRADE, W.J.; PIMENTEL, C.I.P. Análise das atividades de educação ambiental realizadas no Parque Estadual da Cantareira. Revista Instituto Florestal, v. 22, n. 1 p. 93-109, 2010.

INSTITUTO FLORESTAL. Áreas Protegidas: Floresta Estadual de Bebedouro. Disponível em: $<$ http://www.iflorestal.sp.gov.br/areas protegidas/index.asp $>$. Acesso em: 15 jan. 2012.

LAYRARGUES, P.P. Muito prazer sou a educação ambiental, seu novo objeto de estudo sociológico. Anais do I Encontro da Associação Nacional de Pós Graduação e Pesquisa em Ambiente e Sociedade. 6 a 9 de novembro de 2002. (Formato Eletrônico: CD-ROM).

OLIVEIRA, M. J. C.; NADER, S. Comunicação Organizacional e Meio Ambiente: Uma análise sobre a relação entre políticas ambientais e de comunicação. Anais ABRACORP, 12p., 2007.

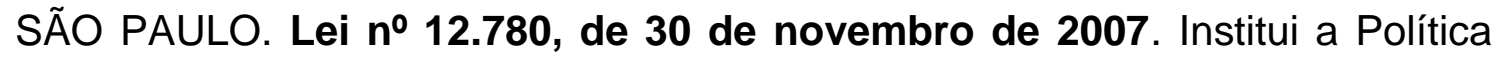
Estadual de Educação Ambiental.

SÃO PAULO. Resolução SMA $\mathrm{n}^{\circ} 17$ de 19 de março de 2008.Altera a Resolução SMA № 21, de 16-05-2007 e dá providências correlatas. Disponível em: $\quad$ http://www.ambiente.sp.gov.br/legislacao/category/resolucoes-sma/. Acesso em: maio de 2014.

SÃO PAULO. Resolução SMA n`18 de 31 de março de 2009. Substitui o Projeto Ambiental "Mutirões Ambientais" pelo Projeto Ambiental "Criança Ecológica" na agenda prioritária da Secretaria do Meio Ambiente e dá providências correlatas. Disponível em: http://www.ambiente.sp.gov.br/legislacao/category/resolucoes-sma/. Acesso em: maio de 2014.

SÃO PAULO. Resolução SMA $n^{\circ} 51$ de 08 de junho de 2010. Projetos Ambientais Estratégicos. Disponível em: http://www.ambiente.sp.gov.br/legislacao/category/resolucoes-sma/. $\quad$ Acesso em: maio de 2014.

SÃO PAULO. Projeto Criança Ecológica. 2010. Disponível em: shttp//www.criancaecologica.sp.gov.br>. Acesso em: dezembro de 2013.

SÃO PAULO. Projeto Município Verde Azul. 2010. Disponível em: shttp://www.ambiente.sp.gov.br/municipioverdeazul/munCert2010.pdf $>$. Acesso em: janeiro de 2014.

Revbea, São Paulo, V. 12, № 1: 12-23, 2017. 
SÃO PAULO. Resolução SMA n`51 de 08 de junho de 2010. Projetos Ambientais Estratégicos. Disponível em: http://www.ambiente.sp.gov.br/legislacao/category/resolucoes-sma/. $\quad$ Acesso em: maio de 2014.

TABANEZ, M.F. Significado para professores de um programa de educação ambiental em unidades de conservação. 2000. 329 f. (Dissertação de Mestrado em Educação) - Centro de Educação e Ciências Humanas, Universidade Federal de São Carlos, São Carlos/SP.

TABANEZ, M.F.; ROSA, P.R.F. Projeto para implantação de área de educação ambiental e recreação na Floresta de Bebedouro - Bebedouro São Paulo. In: TABANEZ, M.F.; ROSA, P.R.F. Programa Nacional do Meio Ambiente. São Paulo: Secretaria de Estado do Meio Ambiente, 1994. 